\title{
Endocrinological Differences between Hatano High- and Low-Avoidance Rats during Early Two-Way Avoidance Acquisition
}

\author{
Sayaka AKIEDA-ASAI ${ }^{1-3)}$, Ryo OHTA ${ }^{4)}$, Mariko SHIROTA ${ }^{5)}$, \\ Sukanya JAROENPORN ${ }^{6}$, Gen WATANABE ${ }^{1,2)}$, and Kazuyoshi TAYA ${ }^{1,2)}$
}

${ }^{1)}$ Department of Basic Science, United Graduate School of Veterinary Sciences, Gifu University, Gifu 501-1193, ${ }^{2}$ Laboratory of Veterinary Physiology, Department of Veterinary Medicine, Faculty of Agriculture, Tokyo University of Agriculture and Technology, Fuchu, Tokyo 183-8509, ${ }^{3)}$ Frontier Science Research Center, University of Miyazaki, 5200 Kiyotake, Miyazaki 889-1692, ${ }^{4}$ Safety Testing Laboratory, Research Administration Hatano Research Institute, Food and Drug Safety Center, Hatano, Kanagawa 257-8523, ${ }^{5)}$ Laboratory of Comparative Toxicology, School of Veterinary Medicine, Azabu University, Kanagawa 229-8501, Japan, and ${ }^{6)}$ Primate Research Unit, Department of Biology,

Faculty of Science, Chulalongkorn University, Bangkok 10330, Thailand

\begin{abstract}
Hatano high (HAA)- and low (LAA)-avoidance rats were selected from SpragueDawley rats genetically on the basis of their active avoidance behavior in a shuttle-box test. The purpose of this study was to investigate stress-related alterations of hormones corticotropin-releasing hormone $(\mathrm{CRH})$, arginine-vasopressin (AVP), prolactin, and adrenocorticotropin (ACTH) in the brain and blood during early avoidance acquisition using two lines of Hatano rats. In paraventricular nucleus (PVN) of the hypothalamus, the CRH levels in HAA rats were significantly increased after shuttle-box tasks compared with before the tasks, whereas the $\mathrm{CRH}$ levels in LAA rats significantly decreased after shuttle-box tasks compared with before the tasks. In the HAA rats, the CRH and AVP levels in the median eminence decreased after shuttle-box tasks, whereas there were no significant differences in the levels between before and after shuttle-box tasks in LAA rats. The plasma concentrations of ACTH were significantly higher in HAA rats than in LAA rats after shuttle-box tasks. These results show that the response of $\mathrm{CRH}-\mathrm{ACTH}$ was higher in HAA rats than in LAA rats. This phenotype may be an important reason for the high avoidance rates of shuttle-box tasks in HAA rats. These endocrine differences in early avoidance acquisition may be involved in regulation of their avoidance responses in the shuttle-box task.
\end{abstract}

Key words: ACTH, AVP, CRH, Hatano rat strains, prolactin 


\section{Introduction}

Two lines of Hatano rats have been genetically selected and bred from Sprague-Dawley rats on the basis of their performance in shuttle-box tasks [31]. High- and low-avoidance animals (HAA and LAA) were selected on the basis of high and low rates of avoidance response, respectively, because the shuttle-box test produced individual differences. The Hatano lines also show differences in maze performance [31], behavioral development [32], and stress-induced gastric ulceration [4]. We previously investigated the effect of cross-fostering on shuttle-box avoidance and the open-field and Biel water maze learning tests [32]. These tests were unaffected by cross-fostering. Therefore, the genetic regulations rather than the epigenetic mechanisms are more important in the two Hatano lines.

Furthermore, these rats have endocrinological strain differences. The responses to restraint stress of the adrenocorticotropin (ACTH) secretions were higher in HAA rats than in LAA rats, and those of the corticosterone and prolactin secretions to restraint stress were lower in HAA rats than in LAA rats [2]. Regulation of endocrine systems in the brain is a complicated process involving stress and memory. In particular, the amygdala and hypothalamus are brain structures that are deeply involved in stress response and regulation of the hypothalamus-pituitary-adrenal (HPA) axis [23, 30]. Corticotropin releasing hormone (CRH) from the paraventricular nucleus (PVN) of the hypothalamus and/or circulating plasma corticosterone change as a consequence of restraint stress [24]. CRH has arousal properties, which are also part of learning and memory [22, 27]. Therefore, we hypothesized that there are strain differences in the hypothalamic and amygdaloid contents and regulation of $\mathrm{CRH}$ in the two lines of Hatano rats during early two-way avoidance acquisition.

CRH increases coproduction, corelease and cosecretion of arginine vasopressin (AVP) [38], and CRH induces ACTH release from the pituitary gland, which results in the adrenocortical release of corticosterone $[21,35]$. AVP is involved in learning and memory processes, and enhances memory consolidation and retrieval processes $[8,13]$. Passive avoidance behavior is affected by AVP [40]. In the present study, we also fo- cused on the hypothalamic contents of AVP during early two-way avoidance acquisition.

The present study was conducted to clarify strain differences in endocrinological characteristics in the brain of two lines of Hatano rat in relation to the stress and learning of avoidance behavior.

\section{Materials and Methods}

\section{Animals and experimental procedures}

The animal experiment in this study was conducted in accordance with "Guideline for Animal Experiment in Hatano Research Institute, Food and Drug Safety Center."

Adult male rats (13-15 weeks) from each strain, HAA rats $(n=53)$ and LAA rats $(n=49)$, were used. The animals were kept under a 12-h light-dark cycle (lights on from 7:00 AM to 19:00 PM) at a temperature of $23-25^{\circ} \mathrm{C}$ and relative humidity of $55 \pm 5 \%$. Food (CE-2, Clea Japan, Inc., Tokyo, Japan) and water were available $a d$ libitum. Animals were killed by decapitation before and after shuttle-box test. Trunk blood was collected in heparinized tubes containing aprotinin and centrifuged immediately, and plasma was separated and stored at $-20^{\circ} \mathrm{C}$ until assayed for ACTH and corticosterone. Brains were frozen on dry ice, and punched hypothalamic amygdala and PVN were obtained from $50-\mu \mathrm{m}$ cryostat sections [36]. The stalk-median eminence was dissected with a pair of fine scissors under a stereoscopic microscope. These tissues and the anterior and posterior pituitary glands were homogenized in $1 \mathrm{ml}$ of $0.85 \%(\mathrm{~N} / \mathrm{V}) \mathrm{NaCl}$ solution and centrifuged at 25,000 $\times$ $g$ for $30 \mathrm{~min}$ at $4^{\circ} \mathrm{C}$. The supernatants were stored at $-20 \mathrm{C}^{\circ}$ until assayed for CRH, ACTH, and AVP. The pellet was solubilized in $0.5 \mathrm{M}$ PBS and analyzed for protein content by the method of Bradford [7].

\section{Shuttle-box avoidance test}

The rats were tested in a shuttle-box (TX-401L, Unicom Inc., Chiba, Japan) consisting of two $50 \times 20 \times 25$ $\mathrm{cm}(1 \times \mathrm{w} \times \mathrm{h})$ compartments separated by a central hurdle (height $1.8 \mathrm{~cm}$ ). For each trial, a 3-s conditioning stimulus (CS) consisting of a buzzer and light was followed by 3 -s of the unconditioned stimulus consisting of the CS plus a 10-mA electric shock delivered through 
the grid floor. The number of responses in which animals moved to the other side during the CS was recorded. After being initially exposed to a 5-min session of free exploration in the shuttle-box, the rats were submitted to 60 conditioning trials of avoidance conditioning on 3 consecutive days. The avoidance rate was estimated as the ratio of the number of avoidance responses to the number of all trials on Days 1 and 3.

\section{Radioimmunoassay (RIA)}

Concentrations of ACTH [25], corticosterone [39] and CRH [37] were measured by double-antibody RIAs using ${ }^{125}$ I-labeled radioligands as described previously. The intra- and inter-assay coefficients of variation were 11.3 and $11.9 \%$ for $\mathrm{ACTH}$, and 9.8 and $17.5 \%$ for corticosterone, and 9.5 and $16.4 \%$ for $\mathrm{CRH}$, respectively. Concentrations of AVP were measured with a commercial RIA kit purchased from Mitsubishi Chemical Corporation (Tokyo, Japan). The intra- and inter-assay coefficients of variation were 6.9 and $11.2 \%$ for AVP.

\section{Statistical analysis}

All data are expressed as standard errors of means (SEM). Statistical comparison between two strains was performed by two-way analysis of variance (strain $x$ time) for repeated measures followed by Tukey-Kramer tests when appropriate. $P<0.05$ was considered to be statistically significant.

\section{Results}

Avoidance responses (Fig. 1)

A significant interaction of strain $\times$ time (strain $\times$ time, $F_{(1,61)}=4.82, P=0.03$; strain, $F_{(1,61)}=12.70, P=0.0007$; time, $\left.F_{(1,61)}=1.71, P=0.20\right)$ was found. Tukey-Kramer post hoc tests revealed no differences between HAA rats and LAA rats in avoidance rates on Day 1 . The avoidance rates in HAA rats increased significantly on Day 3 compared with Day 1. On the other hand, the avoidance rates in LAA rats did not change between Days 1 and 3 .

\section{Hormone levels in plasma (Fig. 2)}

Plasma concentrations of ACTH (a), prolactin (b), and corticosterone (c) were measured after shuttle-box tests both on Days 1 and 3 compared with before the tests in

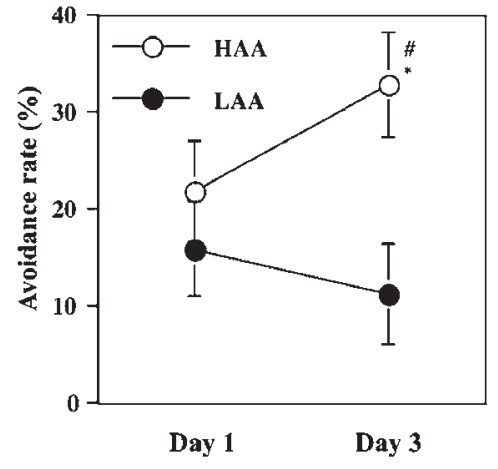

Fig. 1. Avoidance rates in the shuttle-box test on Day 1 and Day 3 in HAA $(O)$ and LAA rats $(\mathbf{O})$. Values are means \pm SEM of five rats. *: $P<0.05$ versus LAA rat. ${ }^{\#}: P<0.05$ versus Day 1 (Tukey-Kramer test).

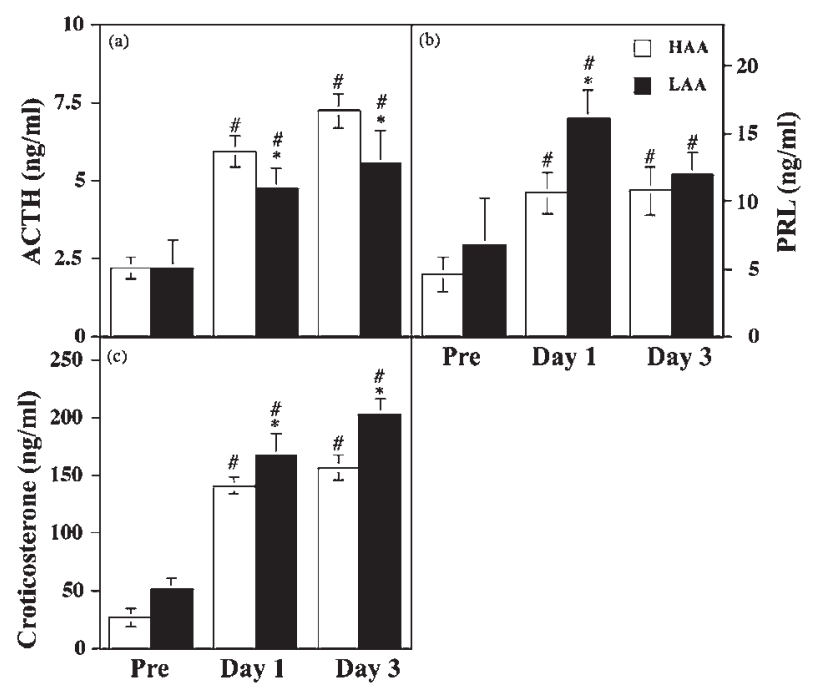

Fig. 2. Effects of shuttle-box test on plasma concentrations of ACTH (a), prolactin (b), and corticosterone (c) in HAA $(\square)$ and LAA rats $(\square)$. Values are means \pm SEM of five rats. *: $P<0.05$ versus HAA rat. ${ }^{\#}: P<0.05$ versus basal levels (Tukey-Kramer test).

both strains. Main effects of strain and time were observed for ACTH, prolactin, and corticosterone, but no interaction effect of strain $\times$ time was found (strain $x$ time, $F_{(1,54)}=1.21, P=0.31$; strain, $F_{(1,54)}=4.63, P=0.04$; time, $F_{(1,54)}=21.05, P<0.0001$, for ACTH; strain $\times$ time, $F_{(1,57)}=0.56, P=0.58$; strain, $F_{(1,57)}=11.07, P=0.002$; time, $F_{(1,57)}=77.58, P<0.0001$, for corticosterone; strain $\times$ time, $F_{(1,46)}=0.05, P=0.96$; strain, $F_{(1,46)}=4.12, P=0.04$; time, $F_{(1,46)}=7.94, P=0.001$ for prolactin). The concen- 
trations of ACTH were higher in HAA rats than in LAA rats after shuttle-box tasks on Days 1 and 3. The concentrations of corticosterone were significantly higher in LAA rats than in HAA rats after shuttle-box tasks on Days 1 and 3. The concentrations of prolactin were significantly higher in LAA rats than in HAA rats after shuttle-box tasks on Day 1.

\section{CRH and AVP levels in amygdala (Fig. 3)}

A main effect of time for CRH levels $\left(F_{(1,22)}=4.87\right.$, $P=0.02)$ was found, but no main effects were observed for strain $\left(F_{(1,22)}=0.30, P=0.59\right)$ or strain $\times$ time $\left(F_{(1,22)}\right.$ $=1.67, P=0.21)$ in the amygdala. The concentrations of CRH in LAA rats significantly decreased after shuttlebox tasks on Days 1 and 3 as compared with before the tasks, whereas a reduction in the $\mathrm{CRH}$ concentrations in HAA rats was observed only on Day 1 after the shuttlebox test (a). No main effects of strain $\times$ time, strain or time were found for the AVP levels (strain $\times$ time, $F_{(1,23)}$ $=0.25, P=0.78 ;$ strain, $F_{(1,23)}=0.001, P=0.98 ;$ time, $F_{(1,23)}$ $=2.75, P=0.09)$ in the amygdala.

\section{CRH levels in the PVN (Fig. 4)}

A main effect of strain $\times$ time for $\mathrm{CRH}$ in the PVN $\left(F_{(1,22)}=3.67, P=0.04\right)$ was observed. The concentrations of CRH were significantly higher in LAA rats than in HAA rats before the shuttle-box tasks. The CRH levels in HAA rats were significantly increased after the shuttlebox tasks on Day 3 as compared with before the tasks, whereas the CRH levels in LAA rats were significantly decreased after shuttle-box tasks on Day 3 compared with before the tasks.

\section{CRH and AVP levels in the median eminence (Fig. 5)}

Main effects of strain and time were found for $\mathrm{CRH}$ in the median eminence, but no interaction effect of strain $\times$ time was observed (strain $\times$ time, $F_{(1,54)}=2.18$, $P=0.12$; strain, $F_{(1,54)}=5.21, P=0.03$; time, $F_{(1,54)}=7.64$, $P=0.001)$. Furthermore, significant interaction of strain $\times$ time was observed for AVP in the median eminence (strain $\times$ time, $F_{(1,22)}=3.84, P=0.04$ ). The concentrations of CRH and AVP were significantly lower in LAA rats than in HAA rats before the shuttle-box tasks.

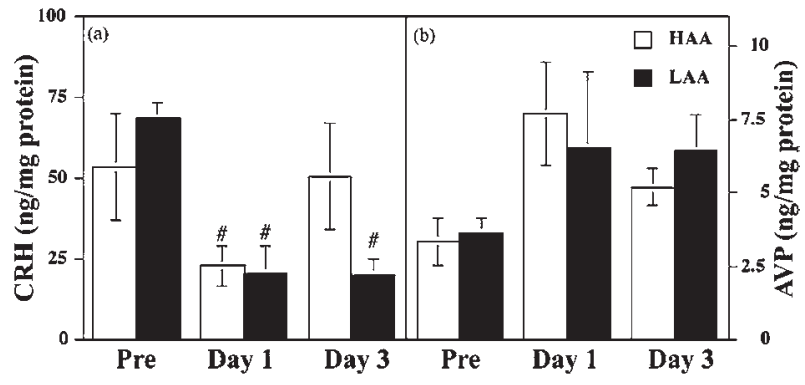

Fig. 3. Effects of shuttle-box test on amygdala concentrations of CRH (a) and AVP (b) in HAA ( $\square$ ) and LAA rats ( $\square$ ). Values are means \pm SEM of five rats. ${ }^{\#:} P<0.05$ versus basal levels (Tukey-Kramer test).

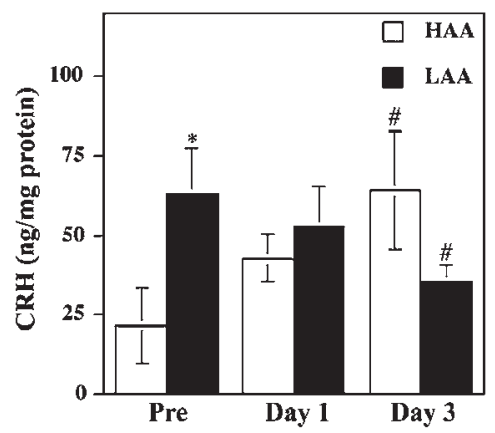

Fig. 4. Effects of shuttle-box test on PVN concentrations of CRH in HAA $(\square)$ and LAA rats $(\square)$. Values are means \pm SEM of five rats. *: $P<0.05$ versus HAA rat. ${ }^{\#}: P<0.05$ versus basal levels (Tukey-Kramer test).

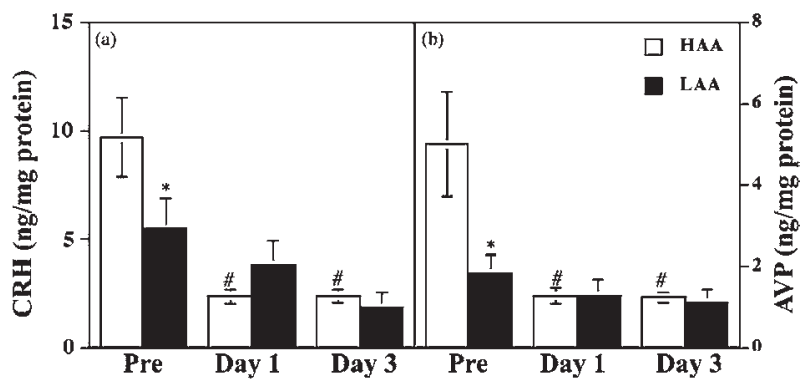

Fig. 5. Effects of shuttle-box test on median eminence concentrations of CRH (a) and AVP (b) in HAA ( $\square$ ) and LAA rats $(\square)$. Values are means \pm SEM of five rats. $*: P<0.05$ versus HAA rat. \#: $P<0.05$ versus basal levels (TukeyKramer test). 


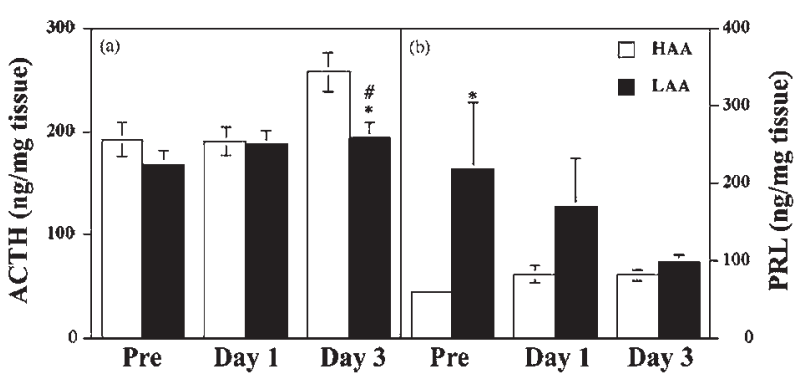

Fig. 6. Effects of shuttle-box test on pituitary concentrations of ACTH (a) and prolactin (b) in HAA ( $\square$ ) and LAA rats $(\square)$. Values are means \pm SEM of five rats. $*: P<0.05$ versus HAA rat. "\# $P<0.05$ versus basal levels (Tukey-Kramer test).

\section{Hormone levels in pituitary glands (Fig. 6)}

Main effects of strain and time were found for ACTH, but no interaction effect of strain $\times$ time was observed (strain $\times$ time, $F_{(1,54)}=2.50, P=0.09$; strain, $F_{(1,54)}=10.92$, $P=0.002$; time, $\left.F_{(1,54)}=4.62, P=0.01\right)$ in the pituitary gland. The concentrations of ACTH were significantly increased after shuttle-box tasks on Day 3 as compared with before the tasks in HAA rats, whereas there were no significant differences in ACTH levels between before and after shuttle-box tasks in LAA rats (a). The concentrations of ACTH were significantly lower in LAA rats than in HAA rats after shuttle-box tasks on the Day 3. Main effects of strain were observed for prolactin, but no interaction effect of time or strain $\times$ time was found (strain $\times$ time, $F_{(1,54)}=2.43, P=0.10$; strain, $F_{(1,54)}=8.87$, $P=0.004$; time, $\left.F_{(1,54)}=1.51, P=0.23\right)$ in the pituitary gland. The pituitary concentrations of prolactin were significantly higher in LAA rats than in HAA rats before shuttle-box tasks (b). The prolactin levels in LAA rats tended to be lower after shuttle-box tasks than before the tasks.

\section{Discussion}

The present study clearly demonstrated that HAA rats and LAA rats have differences in the pattern of hypothalamic hormonal secretion and circulating hormone levels during early avoidance acquisition (Fig. 7). Synthesized $\mathrm{CRH}$ and AVP in parvocellular neurons of the PVN coordinate HPA system activity and project to the external layer of the median eminence, where CRH and AVP are released into the portal blood [1]. The CRH and AVP are the primary hypothalamic and hypophysiotropic factors regulating basal and stress-induced release of pituitary ACTH and mediating the stress response by activation of the HPA axis [29,34]. Before shuttle-box tasks, the concentrations of CRH in the PVN were significantly higher in LAA rats than in HAA rats (Fig. 4). The CRH levels in HAA rats were significantly increased after shuttle-box tasks on Day 3 before the tasks, whereas the CRH levels in LAA rats significantly decreased after shuttle-box tasks on Day 3 compared with before

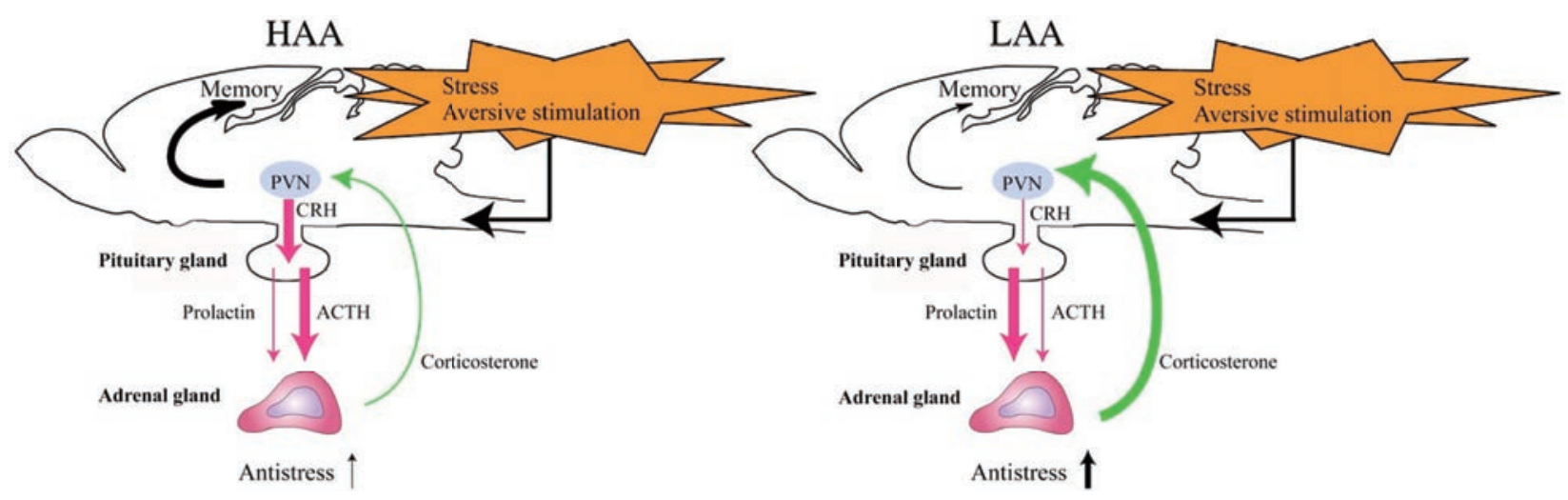

Fig. 7. Proposed mechanisms of the effect of the HPA axis on stress or aversive stimulation in HAA and LAA rats. There is a clear difference in regulation of the hypothalamic-pituitary-adrenal axis between HAA and LAA rats. In HAA rats, ACTH is the major stimulator of the adrenal cortex to secrete corticosterone, and PRL is an important hormone in regulation of corticosterone; on the other hand, PRL is an important hormone in regulation of corticosterone secretion in addition to ACTH in LAA rats during stress. 
the tasks. The concentrations of CRH and AVP in the median eminence were significantly lower in LAA rats than in HAA rats before shuttle-box tasks (Fig. 5). In HAA rats, the CRH and AVP levels in the median eminence decreased after shuttle-box tasks, whereas there were no significant differences in the levels between before and after shuttle-box tasks in LAA rats (Fig. 5). Cell bodies of CRH neurons are primarily localized in the PVN. CRH neurons project to the median eminence and release $\mathrm{CRH}$ to the portal vessel. These results suggest that CRH in LAA rats is the sufficiently synthesized in the PVN; however, the secretions of CRH from the median eminence were low.

The plasma concentrations of ACTH were significantly higher in HAA rats than in LAA rats after shuttlebox tasks (Fig. 2). ACTH improves the deficient acquisition of shuttle-box avoidance behavior of hypophysectomized rats, delay extinction of shuttle-box avoidance behavior, and pole-jumping avoidance behavior, and facilitates passive avoidance behavior of intact rats [28]. Therefore, the high avoidance rate of shuttlebox tasks in HAA rats may be due to the high response of CRH-ACTH.

On the other hand, the adrenal response of corticosterone release to ACTH secretion after shuttle-box tasks was higher in LAA rats than in HAA rats on Day 3 (Fig. 2 ), as found in the previous study of restraint stress [3, 4]. These results indicate that the response of $\mathrm{CRH}-$ ACTH is higher in HAA rats than in LAA rats, whereas the response of corticosterone is lower in HAA rats than in LAA rats. Stress-evoked increases in the plasma corticosterone are correlated with impaired memory in a hippocampal-dependent task [42], and mineralocorticoid receptors are indispensable for nongenomic modulation of hippocampal glutamate transmission by corticosterone [26]. The high response of corticosterone to stress or the differential expression levels of central mineralocorticoid receptors may be a reason the low avoidance rates of shuttle-box tasks in LAA rats.

Prolactin is an antistress hormone [14, 18, 19]. Stress induces the expression of the long-form of the prolactin receptors in choroid plexus and PVN cells $[4,17,19]$. Administration of prolactin into the cerebral ventricles prevents stress-induced formation of gastric ulcers and shows antidepressant effects during forced swimming
[14-16]. Formation of gastric ulcers is observed more frequently in HAA rats than in LAA rats $7 \mathrm{~h}$ after restraint stress in water, whereas the plasma prolactin levels and numbers of long-form prolactin receptors in the PVN are significantly increased in LAA rats than in HAA rats [3,4]. In agreement with the previous studies, the secretion of prolactin was higher in LAA rats than in HAA rats in the present study (Figs. 2 and 6). Thus, LAA rats may be resistant to stress compared with HAA rat.

It is also known that Roman and Syracuse rats, which were selectively bred for differential shuttle-box acquisition, originated from the Wistar and Long-Evans strains, respectively [6,9]. In Roman and Syracuse rats, the response of the hypothalamo-pituitary-adrenal axis is lower in high-avoidance rats than in low-avoidance rats during stress $[5,10,12,20,41]$. The Roman and Syracuse rat strains differ in terms of anxiety, and this is one of the reasons for different results for avoidance behavior [11, 43]. The low avoidance rats of Roman lines display mostly freezing responses in the shuttlebox. However, Hatano LAA rats do not display freezing, anxiety behavior and depression behavior [32, 33]. Therefore, Hatano rats have characteristics that differ from those of Roman and Syracuse rats.

In summary, the present study clearly demonstrated strain differences in the characteristics of brain hormone responses between the two Hatano lines during early avoidance acquisition. The response of CRH-ACTH was higher in HAA rats than in LAA rats. This phenotype may be one of the important reasons for high avoidance rates of shuttle-box tasks in HAA rats. These two Hatano rats may be useful animals for study of the effects of stress-induced hormones on memory and retention regardless of anxiety and depression.

\section{Acknowledgments}

We thank Dr. Atsushi Tohei for advice on CRH measurement. This work was supported by a Grant-in-Aid for Scientific Research (B-1831044; Japan and Thailand Joint Research) from the Japan Society for the Promotion of Science. 


\section{References}

1. Antoni, F.A. 1993. Vasopressinergic control of pituitary adrenocorticotropin secretion comes of age. Front Neuroendocrinol. 14: 76-122.

2. Asai, S., Ohta, R., Shirota, M., Tohei, A., Watanabe, G., and Taya, K. 2004. Endocrinological responses during suckling in Hatano high- and low-avoidance rats. J. Endocrinol. 182: 267-272.

3. Asai, S., Ohta, R., Shirota, M., Watanabe, G., and Taya, K. 2004. Differential responses of the hypothalamo-pituitaryadrenocortical axis to acute restraint stress in Hatano highand low-avoidance rats. J. Endocrinol. 181: 515-520.

4. Asai, S., Ohta, R., Fujikawa, T., Sakai, R.R., Shirota, M., Ogata, M., Watanabe, G., and Taya, K. 2006. Gastric ulceration and expression of prolactin receptor in the brain in Hatano high- and low-avoidance rats. Endocrine 30: 161-166.

5. Aubry, J.M., Bartanusz, V., Driscoll, P., Schulz, P., Steimer, T., and Kiss, J.Z. 1995. Corticotropin-releasing factor and vasopressin mRNA levels in roman high- and low-avoidance rats: response to open-field exposure. Neuroendocrinology 61: 89-97.

6. Bignami, G. 1965. Selection for high rates and low rates of avoidance conditioning in the rat. Anim. Behav. 13: 221227.

7. Bradford, M.M. 1976. A rapid and sensitive method for the quantitation of microgram quantities of protein utilizing the principle of protein-dye binding. Anal. Biochem. 72: 248254.

8. Brattstrom, A., de Jong, W., and De Wied, D. 1990. Central vasopressin impairs the baroreceptor heart rate reflex in conscious rats. J. Cardiovasc. Pharmacol. 15: 114-117.

9. Brush, F.R., Froehlich, J.C., and Sakellaris, P.C. 1979. Genetic selection for avoidance behavior in the rat. Behav. Genet. 9: 309-316.

10. Brush, F.R., Isaacson, M.D., Pellegrino, L.J., Rykaszewski, I.M., and Shain, C.N. 1991. Characteristics of the pituitaryadrenal system in the Syracuse high- and low-avoidance strains of rats (Rattus norvegicus). Behav. Genet. 21: 3548.

11. Brush, F.R. 2003. Selection for differences in avoidance learning: the Syracuse strains differ in anxiety, not learning ability. Behav. Genet. 33: 677-696.

12. Castanon, N., Dulluc, J., Le Moal, M., and Mormede, P. 1994. Maturation of the behavioral and neuroendocrine differences between the Roman rat lines. Physiol. Behav. 55: 775-782.

13. Croiset, G., Heijnen, C.J., and de Wied, D. 1990. Passive avoidance behavior, vasopressin and the immune system. A link between avoidance latency and immune response. Neuroendocrinology 51: 156-161.

14. Drago, F., Continella, G., Conforto, G., and Scapagnini, U. 1985. Prolactin inhibits the development of stress-induced ulcers in the rat. Life Sci. 36: 191-197.

15. Drago, F., D’Agata, V., Spadaro, F., Grassi, M., and Valerio, C. 1990. Prolactin as a protective factor in stress-induced gastric ulcers. Ann. N.Y. Acad. Sci. 597: 248-251.
16. Drago, F., Pulvirenti, L., Spadaro, F., and Pennisi, G. 1990. Effects of TRH and prolactin in the behavioral despair (swim) model of depression in rats. Psychoneuroendocrinology 15: 349-356.

17. Fujikawa, T., Soya, H., Yoshizato, H., Sakaguchi, K., DohUra, K., Tanaka, M., and Nakashima, K. 1995. Restraint stress enhances the gene expression of prolactin receptor long form at the choroid plexus. Endocrinology 136: 5608-5613.

18. Fujikawa, T., Soya, H., Tamashiro, K.L., Sakai, R.R., McEwen, B.S., Nakai, N., Ogata, M., Suzuki, I., and Nakashima, K. 2004. Prolactin prevents acute stress-induced hypocalcemia and ulcerogenesis by acting in the brain of rat. Endocrinology 145: 2006-2013.

19. Fujikawa, T., Tamura, K., Kawase, T., Mori, Y., Sakai, R.R., Sakuma, K., Yamaguch, A., Ogata, M., Soya, H., and Nakashima, K. 2005. Prolactin receptor knockdown in the rat paraventricular nucleus by a morpholino-antisense oligonucleotide causes hypocalcemia and stress gastric erosion. Endocrinology 146: 3471-3480.

20. Gentsch, C., Lichtsteiner, M., Driscoll, P., and Feer, H. 1982. Differential hormonal and physiological responses to stress in Roman high- and low-avoidance rats. Physiol. Behav. 28: 259-263.

21. Gillies, G.E., Linton, E.A., and Lowry, P.J. 1982. Corticotropin releasing activity of the new CRF is potentiated several times by vasopressin. Nature 299: 355-357.

22. Heinrichs, S.C. and Koob, G.F. 2004. Corticotropin-releasing factor in brain: a role in activation, arousal, and affect regulation. J. Pharmacol. Exp. Ther. 311: 427-440.

23. Imaki, T., Nahan, J.L., Rivier, C., Sawchenko, P.E., and Vale, W. 1991. Differential regulation of corticotropin-releasing factor mRNA in rat brain regions by glucocorticoids and stress. J. Neurosci. 11: 585-599.

24. Inoue, T., Koyama, T., Muraki, A., and Yamashita, I. 1993. Effects of single and repeated immobilization stress on corticotropin-releasing factor concentrations in discrete rat brain regions. Prog. Neuropsychopharmacol. Biol. Psychiatry 17: 161-170.

25. Kanesaka, T., Taya, K., and Sasamoto, S. 1992. Radioimmunoassay of corticosterone using 125I-labeled radioligand. J. Reprod. Dev. 38: 85-89.

26. Khaksari, M., Rashidy-Pour, A., and Vafaei, A.A. 2007. Central mineralocorticoid receptors are indispensable for corticosterone-induced impairment of memory retrieval in rats. Neuroscience 149: 729-738.

27. Kovacs, G.L., Telegdy, G., and Lissak, K. 1977. Dosedependent action of corticosteroids on brain serotonin content and passive avoidance behavior. Horm. Behav. 8: $155-165$.

28. Kovacs, G.L. and De Wied, D. 1994. Peptidergic modulation of learning and memory processes. Pharmacol. Rev. 46: 269-291.

29. Meaney, M.J., Diorio, J., Francis, D., Widdowson, J., LaPlante, P., Caldji, C., Sharma, S., Seckl, J.R., and Plotsky, P.M. 1996. Early environmental regulation of forebrain glucocorticoid receptor gene expression: implications for adrenocortical responses to stress. Dev. Neurosci. 18: 49- 
72.

30. Merlo Pich, E., Lorang, M., Yeganeh, M., Rodriguez de Fonseca, F., Raber, J., Koob, G.F., and Weiss, F. 1995. Increase of extracellular corticotropin-releasing factor-like immunoreactivity levels in the amygdala of awake rats during restraint stress and ethanol withdrawal as measured by microdialysis. J. Neurosci. 15: 5439-5447.

31. Ohta, R., Matsumoto, A., Hashimoto, Y., Nagao, T., and Mizutani, M. 1995. Behavioral characteristics of rats selectively bred for high and low avoidance shuttlebox response. Congenital Anomalies 35: 223-229.

32. Ohta, R., Matsumoto, A., Nagao, T., and Mizutani, M. 1998. Comparative study of behavioral development between high and low shuttlebox avoidance rats. Physiol. Behav. 63: $545-551$.

33. Ohta, R., Shirota, M., Adachi, T., Tohei, A., and Taya, K. 1999. Plasma ACTH levels during early, two-way avoidance acquisition in high- and low-avoidance rats (Hatano strains). Behav. Genet. 29: 137-144.

34. Owens, M.J., and Nemeroff, C.B. 1991. Physiology and pharmacology of corticotropin-releasing factor. Pharmacol. Rev. 43: 425-473.

35. Rivier, C., Rivier, J., Mormede, P., and Vale, W. 1984. Studies of the nature of the interaction between vasopressin and corticotropin-releasing factor on adrenocorticotropin release in the rat. Endocrinology 115: 882-886.

36. Schwartz, M.W., Sipols, A.J., Marks, J.L., Sanacora, G., White, J.D., Scheurink, A., Kahn, S.E., Baskin, D.G., Woods, S.C., and Figlewicz, D.P. 1992. Inhibition of hypothalamic neuropeptide Y gene expression by insulin. Endocrinology 130: 3608-3616.
37. Suda, T., Tomori, N., Sumitomo, T., Nakagami, Y., Tozawa, F., Ushiyama, T., Demura, H., and Shizume, K. 1987. Radioimmunoassay of corticotropin-releasing hormone: methodology and clinical application. Horm. Metab. Res. Suppl. 16: 47-51.

38. Tilders, F.J., Schmidt, E.D., and de Goeij, D.C. 1993. Phenotypic plasticity of CRF neurons during stress. Ann.N. Y. Acad. Sci. 697: 39-52.

39. Tomabechi, T., Taya, K., Akai, M., and Sasamoto, S. 1994. A radioimmunoassay for adrenocorticotropic hormone (ACTH) in unextracted plasma of various animals. J. Reprod. Dev. 40: 99-104.

40. van Wimersma Greidanus, T.B., van Ree, J.M., and de Wied, D. 1983. Vasopressin and memory. Pharmacol. Ther. 20: 437-458.

41. Walker, C.D., Rivest, R.W., Meaney, M.J., and Aubert, M.L. 1989. Differential activation of the pituitary-adrenocortical axis after stress in the rat: use of two genetically selected lines (Roman low- and high-avoidance rats) as a model. $J$. Endocrinol. 123: 477-485.

42. Woodson, J.C., Macintosh, D., Fleshner, M., and Diamond, D.M. 2003. Emotion-induced amnesia in rats: working memory-specific impairment, corticosterone-memory correlation, and fear versus arousal effects on memory. Learn. Mem. 10: 326-336.

43. Yilmazer-Hanke, D.M., Faber-Zuschratter, H., Linke, R., and Schwegler, H. 2002. Contribution of amygdala neurons containing peptides and calcium-binding proteins to fearpotentiated startle and exploration-related anxiety in inbred Roman high- and low-avoidance rats. Eur. J. Neurosci. 15: 1206-1218. 